\title{
ACUTE MECHANICAL INJURY OF THE HUMAN INTERVERTEBRAL DISC: LINK TO DEGENERATION AND PAIN
}

\author{
B. Alkhatib ${ }^{1, \S}$, D.H. Rosenzweig ${ }^{1, \S}$, E. Krock ${ }^{1}$, P.J. Roughley ${ }^{2}$, L. Beckman ${ }^{1}$, T. Steffen ${ }^{1}$, M.H. Weber ${ }^{3}$, J.A. Ouellet ${ }^{3}$ \\ and L. Haglund*1,3
}

\author{
${ }^{1}$ Orthopeadic Research Laboratory, Division of Orthopedic Surgery, McGill University, Montreal, Canada \\ ${ }^{2}$ Shriners Hospital for Children, Montreal, Canada \\ ${ }^{3}$ McGill Scoliosis and Spine Research Group, Montreal, Canada
}

$\S$ These authors contributed equally

\begin{abstract}
Excessive mechanical loading or acute trauma to intervertebral discs (IVDs) is thought to contribute to degeneration and pain. However, the exact mechanisms by which mechanical injury initiates and promotes degeneration remain unclear. This study investigates biochemical changes and extracellular matrix disruption in whole-organ human IVD cultures following acute mechanical injury. Isolated healthy human IVDs were rapidly compressed by $5 \%$ (non-injured) or $30 \%$ (injured) of disc height. $30 \%$ strain consistently cracked cartilage endplates, confirming disc trauma. Three days post-loading, conditioned media were assessed for proteoglycan content and released cytokines. Tissue extracts were assessed for proteoglycan content and for aggrecan integrity. Conditioned media were applied to PC12 cells to evaluate if factors inducing neurite growth were released. Compared to controls, IVD injury caused significant cell death. Injury also caused significantly reduced tissue proteoglycan content with a reciprocal increase of proteoglycan content in culture media. Increased aggrecan fragmentation was observed in injured tissue due to increased matrix metalloproteinase and aggrecanase activity. InjuredIVD conditioned media contained significantly elevated interleukin (IL)-5, IL-6, IL-7, IL-8, MCP-2, GRO $\alpha$, and MIG, and ELISA analysis showed significantly increased nerve growth factor levels compared to non-injured media. Injured-disc media caused significant neurite sprouting in PC12 cells compared to non-injured media. Acute mechanical injury of human IVDs ex vivo initiates release of factors and enzyme activity associated with degeneration and back pain. This work provides direct evidence linking acute trauma, inflammatory factors, neo-innervation and potential degeneration and discogenic pain in vivo.
\end{abstract}

Keywords: Intervertebral disc, mechanical injury, inflammation, extracellular matrix, degeneration, nerve growth factor.

*Address for correspondence:

Lisbet Haglund

McGill University Health Centre, Department of Surgery, Montreal General Hospital, Room C9.173, 1650 Cedar Ave, Montreal, QC H3G 1A4,

Telephone number: (514) 9341934 ext. 35380

E-mail: lisbet.haglund@mcgill.ca

\section{Introduction}

Intervertebral disc (IVD) degeneration is a debilitating disease directly contributing to low back pain and accounts for tremendous healthcare costs world-wide (Manchikanti et al., 2009). IVDs function to provide load-bearing and range of motion to the trunk, neck and head. IVDs are comprised of a gelatinous nucleus pulposus (NP) and the fibro-cartilaginous annulus fibrosus (AF), which forms concentric rings around the central NP (Roughley, 2004). The porous cartilaginous endplates (EPs) cap the disc both cranially and caudally acting as a barrier between disc tissue and the vertebral bodies, allowing nutrient and waste diffusion into and out of the disc. The extracellular matrix (ECM) of the disc is composed mainly of collagen and proteoglycan, which contribute to disc mechanical properties (Gardner-Morse and Stokes, 2004; Roughley, 2004). NP and AF cells are responsible for balancing anabolic and catabolic turnover towards ECM maintenance.

IVD degeneration occurs when there is a catabolic shift whereby NP and AF cells synthesise more matrixdegrading enzymes than ECM components. One hallmark of ECM degradation is cleavage and loss of the abundant proteoglycan aggrecan, which gives the NP its high water content and compressive resistance (Adams and Roughley, 2006). Ultimately, matrix degradation leads to a combination of IVD mechanical dysfunction, cell death and inflammation. Disc degeneration is thought to result from several factors including trauma, disc prolapse or herniation, genetic factors, lifestyle, smoking, and atherosclerosis (Kelsey et al., 1984; Battie et al., 1991; Videman et al., 1995; Adams and Roughley, 2006). However, the exact events and initiating mechanisms of IVD degeneration are poorly understood.

The inflammatory response observed during IVD degeneration has been hypothesised to modulate degradation of the ECM during disease progression. Inflammatory factors released by disc cells can act to increase expression of matrix-degrading catabolic enzymes such as matrix metalloproteinases (MMP) and aggrecanases (ADAMTS) (Le Maitre et al., 2005; Phillips et al., 2013). Disruption of ECM integrity and loss in disc height or disc herniation can lead to nerve impingement and neuropathic pain (Freemont et al., 2002). Studies have indicated that increased inflammatory factors can promote neurite outgrowth and sensitise neurons (Richardson et al., 2012; Wuertz and Haglund, 2013; Gawri et al., 2014; Krock et al., 2014), which is directly related to painful disc degeneration in patients. Furthermore, annulus fissures 
have been demonstrated to allow for a focal proteoglycan loss leading to nerve and blood vessel ingrowth which can cause pain (Stefanakis et al., 2012). Pro-inflammatory and pro-nociceptive factors found to be increased in these patients include interleukin-1 beta (IL-1 $\beta$ ), IL-6, IL-8, tumour necrosis factor alpha (TNF- $\alpha$ ), nerve growth factor (NGF) and brain derived neurotrophic factor (BDNF) (Freemont et al., 2002; Purmessur et al., 2008; Gruber et al., 2012; Krock et al., 2014). Interestingly, an inflammatory response can be activated by adverse mechanical stimulation at the cellular level (Gilbert et al., 2010; Gawri et al., 2014) as well as the intact disc level in animal models (Miyagi et al., 2012). Vertebral endplate fracture has also been linked to increased catabolic enzyme and pro-inflammatory gene expression (Wang et al., 2012; Fields et al., 2014). Taken together, these recent studies strongly suggest a biomechanical role in initiation and progression of IVD inflammation, degeneration and pain.

Research investigating the role of inflammation in painful human disc degeneration has focused on analysis of surgically removed degenerate IVD samples or cadaveric IVD samples at various times post-mortem (Richardson et al., 2009; Gruber et al., 2010; Richardson et al., 2012; Phillips et al., 2013; Krock et al., 2014), usually from tissue that is already degenerate. Several recent studies utilising ex vivo (Iatridis et al., 2005; Walter et al., 2011; Dudli et al., 2012) and in vivo (Miyagi et al., 2012) animal models have established a strong correlation between injurious mechanical loading in IVD degeneration. However, no studies to-date have been able to analyse in real-time the events underlying degeneration to otherwise healthy human whole-disc organ cultures - and it is therefore pertinent to generate a mechanical overload model of human IVDs to better link animal model data to human disease.

This study demonstrates the consequences of a single high-impact traumatic loading event on human intervertebral discs with intact cartilaginous endplates. Here, traumatic loading was applied to healthy human intervertebral discs, and cell viability, matrix disruption and inflammatory responses were assessed to determine if acute mechanical trauma ex vivo initiates events associated with IVD degeneration and pain.

\section{Materials and Methods}

\section{Materials}

Dulbecco's Modified Eagle Medium (DMEM), Tween20, BSA, Safranin-O, Fast Green, dimethylmethylene blue, rat tail collagen type I and Poly-L-Lysine were purchased from
Sigma (Burlington, ON, Canada). LIVE/DEAD assay was purchased from Invitrogen (Eugene, OR, USA). Methanol was purchased from VWR (Radnor, PA, USA). EDTAfree protease inhibitor tablets were purchased from Roche (Indianapolis, IN, USA). Keratanase II and Chondroitinase ABC were purchased from AMS biotechnology (Lake Forest, CA, USA). Novex 4-12\% Tris-Glycine gradient gels were purchased from Life Technologies (Carlsbad, CA, USA). Carnation Skim Milk Powder was used to block membranes for Western blot (Markham, ON, Canada). Rabbit IgG secondary antibody was purchased from Cell Signaling Technology (Danvers, MA, USA). PC12 cells were purchased from American Type Culture Collection (ATCC) (Manassas, VA, USA). Roswell Park Memorial Institute (RPMI) 1640 medium, Antibiotic-Antimycotic Solution, Foetal Bovine Serum, and Horse Serum were purchased from Life Technologies (Gibco) (Carlsbad, CA, USA). Western Lightning Plus Electrochemiluminescence Kit was purchased from Perkin Elmer (Waltham, MA, USA). Recombinant Neuronal Growth Factor (bNGF) was purchased from BioShop (Burlington, ON, Canada). Human Cytokine Array 1 Map (product code: AAHCYT-1), NGF ELISA (ELH-BNGF-001), BDNF ELISA (ELH-BDNF-001), and IL-1 $\beta$ ELISA(ELH-IL1BETA-001) were all purchased from RayBiotech (Norcross, GA, USA). Aggrecan antibodies recognising the G1 domain (G1), the matrix metalloproteinase (MMP)-generated neoepitope (MMP-neo) and the aggrecanase generated neoepitope (AGCN-neo) used for immunoblotting were prepared as described previously (Roughley et al., 2012).

\section{Tissue source}

With approval of the McGill University institutional review board, and in collaboration with the provincially run organ donation program: Transplant Quebec, three human lumbar spines were harvested en bloc using a standardised sterile surgical technique, and a total of 2 discs per donor were obtained (age 21, 34 and 47 - Table 1), and each donor acted as its own control. Strict selection criteria were followed ensuring that only healthy IVD were selected for this study. All donors had no history of back-pain based on an in-house Transplant Quebec-approved questionnaire, and all spines were visually and radiographically examined for any signs of degeneration. The harvest procedure was performed within $6 \mathrm{~h}$ of clamping of the aorta. Discs were extracted from the lower lumbar segment (Table 1) and cultured leaving the cartilaginous endplates intact using a previously described culture method (Gawri et al., 2011). Briefly, discs were isolated by parallel cuts in the adjacent vertebral bodies close (within $0.5 \mathrm{~cm}$ ) to the cartilaginous

Table 1. Demographics of donors and disc levels used in the study.

\begin{tabular}{|c|c|c|c|c|c|c|}
\hline Donor & Age (years) & Disc level & Compression & Surface area $\left[\mathbf{c m}^{2}\right]$ & Height at 100 N [cm] & Weight [g] \\
\hline \multirow{2}{*}{1} & \multirow{2}{*}{47} & L 3-4 & Non-injured & 16.60 & 1.57 & 18.2 \\
\cline { 3 - 7 } & \multirow{2}{*}{2} & L 4-5 & Injured & 17.01 & 1.64 & 20.1 \\
\cline { 3 - 7 } & \multirow{2}{*}{21} & T 11-12 & Non-injured & 10.30 & 1.05 & 10.4 \\
\cline { 3 - 7 } & \multirow{2}{*}{3} & L 1-2 & Injured & 12.70 & 1.30 & 14,1 \\
\cline { 3 - 7 } & \multirow{2}{*}{35} & L 12 - L 1 & Non-injured & 14.10 & 1.74 & 30.3 \\
\hline
\end{tabular}


A
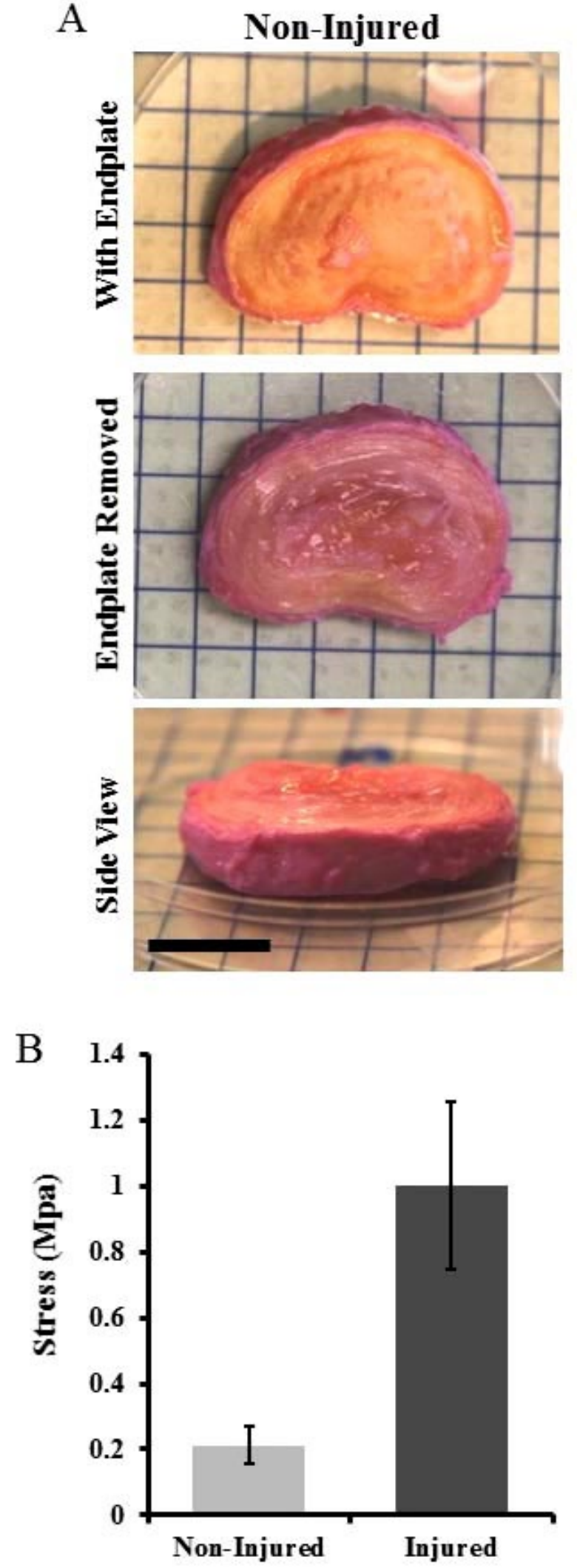

Injured
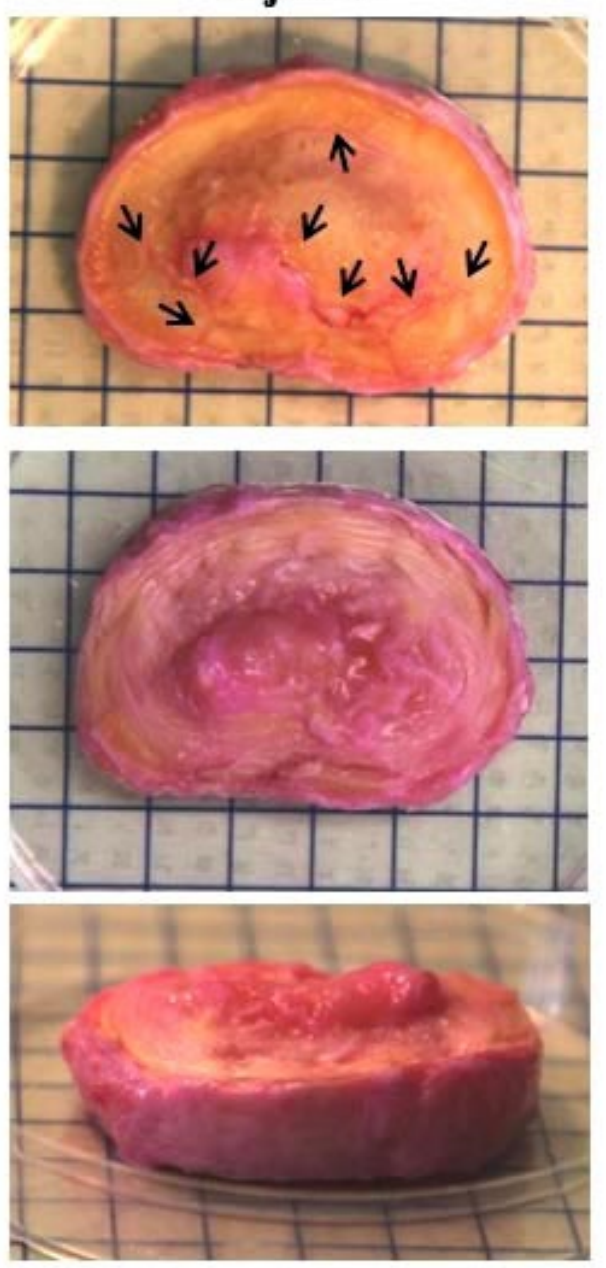

$\mathrm{C}$

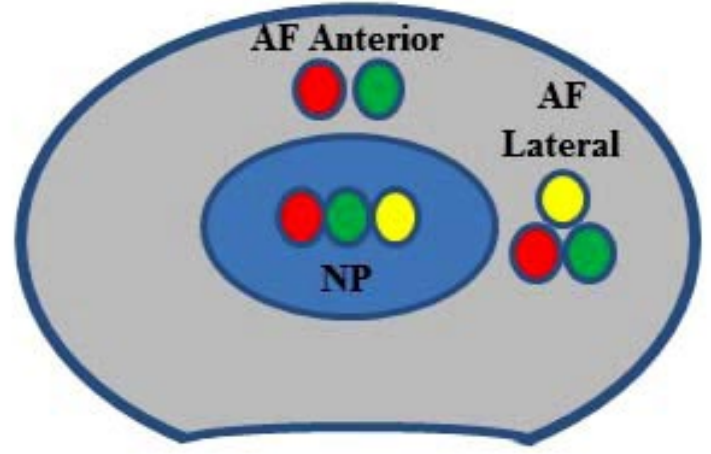

Fig. 1. A single-ramp compression consistently cracks cartilaginous endplates of healthy human IVDs. (A) Representative macroscopic view of IVD damage after non-injurious (5\% strain) and injurious (30 \% strain) load. Top panels show discs with endplates. Lower panels show different views of the same samples with endplates removed (14 days post-loading). Arrows indicate large fissures in endplate. Scale bar represents $2 \mathrm{~cm}$. (B) Measured average peak stress for non-injurious and injurious load. $n=3$ for each group. Error bars indicate \pm SD. (C) Schematic indicating where biopsy punches were taken from discs for further analysis. Red circles indicate samples taken for viability assays, green circles indicate samples taken for protein/proteoglycan extractions, and yellow circles indicate samples taken for histology. 
endplate. A high speed bone burr (Series SR Foredom, Bethel, CT, USA) was used to remove all bone until only the cartilage endplate was remaining.

Following the termination of the 14 day culture period, the endplates were removed in order to macroscopically visualise damage to the underlying tissue following compression. Endplates were lifted at one lateral end with forceps and a surgical blade was used to dismember them from the disc tissue beneath. Initially, endplate was removed from the annulus fibrosus on all sides, and then proceeding to the remaining portion where the endplate covering the nucleus pulposus was removed, thereby allowing easier core punches to be taken for tissue analysis.

\section{Loading protocol}

Using a Mini Bionix 858 MTS machine, isolated discs were held under a mild load of $100 \mathrm{~N}$ for $2 \mathrm{~min}$ to assess disc height. Discs were then subjected to a single compression of either $5 \%$ (non-injured) or $30 \%$ (injured) strain at a rate of $30 \%$ per second. Each donor had one disc serving as control and one serving as injured. Average peak stress achieved was $0.212 \pm 0.056 \mathrm{MPa}$ (non-injured) or $1.002 \pm 0.256 \mathrm{MPa}$ (injured) (Fig. 1B). $30 \%$ injurious compression consistently yields endplate fracture (Fig. 1A, arrows). These particular loading schemes were chosen to simulate non-injurious $(5 \%-\sim 0.2 \mathrm{MPa})$ and acute hyperphysiological (30\%- 1.0 MPa) compressions respectively. It also allowed the two groups to be manipulated in the same way with the only difference being load magnitude. Discs were immediately placed in $3.5 \mathrm{~mL}$ culture medium per gram of tissue (Gawri et al., 2011) (DMEM containing $4.5 \mathrm{~g} / \mathrm{L}$ glucose and supplemented with $1 \%$ foetal calf serum (FCS), $25 \mathrm{mmol} / \mathrm{L}$ HEPES, $0.25 \mu \mathrm{g} / \mathrm{mL}$ fungizone, $50 \mu \mathrm{g} / \mathrm{mL}$ L-ascorbate, $2 \mathrm{mmol} / \mathrm{L}$ GlutaMAX and $50 \mu \mathrm{g} / \mathrm{mL}$ gentamicin sulphate) for up to 14 days with media changes every 3 days.

\section{Cell viability}

Three separate $6 \mathrm{~mm}$ tissue cores were excised from both non-injured and injured discs. Two AF cores (anterior and lateral AF) and $1 \mathrm{NP}$ core were excised (Fig. 1C, red circles). Viability was determined by LIVE/DEAD assay prepared in Serum-free DMEM according to manufacturer's instructions. A custom blade tool was used to prepare tissue slices for analysis as previously described (Haglund et al., 2011) and samples were visualised and quantified using an inverted confocal laser scanning microscope (CLSM, Zeiss LSM 510) as previously described (Haglund et al., 2011). PC12 cell viability was assessed by LIVE/DEAD assay and quantified from 3 random positions from 3 independent experiments using images obtained on an Olympus IX81 (Tokyo, Japan) inverted fluorescence microscope. All images were captured using a 20x objective with MAG Biosystems Software 7.5 (Photometrics, Tucson, AZ, USA).

\section{Proteoglycan analysis}

Sulphated glycosaminoglycans (GAGs) were quantified from culture media by a modified dimethyl methylene blue (DMMB) assay (Mort and Roughley, 2007). Samples were diluted to fall in the middle of the linear range of the standard curve and results expressed per mL medium. To quantify GAG remaining in the disc tissue post-loading, $2 \mathrm{AF}$ (anterior and posterior AF) $6 \mathrm{~mm}$ tissue cores and 1 central NP tissue core (Fig. 1C, green circles) were extracted at $4{ }^{\circ} \mathrm{C}$ for $48 \mathrm{~h}$ in 15 volumes (per mg tissue wet weight) of $4 \mathrm{M}$ guanidine hydrochloride $(\mathrm{GuHCl})$, $50 \mathrm{mM}$ sodium acetate, $\mathrm{pH} 5.8,10 \mathrm{mM}$ EDTA and protease inhibitors. In order to adjust for any interference by $\mathrm{GuHCl}$, an equivalent amount of $4 \mathrm{M} \mathrm{GuHCl}$ was added to standards. Results were normalised to tissue wet weight.

\section{Immunoblotting}

For immunoblotting, only NP tissue was analysed since it normally contains the highest amount of proteoglycan in the disc. Aliquots of $8 \mu \mathrm{L}$ of NP tissue extract (described above) were prepared for SDS-PAGE by precipitation using 9 volumes of $100 \%$ ethanol. Precipitates were recovered by centrifugation $\left(30 \mathrm{~min}\right.$ at $4{ }^{\circ} \mathrm{C}$ ). Pellets were washed once each with $75 \%$ ethanol and $95 \%$ ethanol before being lyophilised and re-dissolved in $25 \mu \mathrm{L}$ $50 \mathrm{mM}$ sodium acetate, $\mathrm{pH}$ 6.0. Resuspended protein was then digested with keratanase II at $1 \mu \mathrm{L} / 25 \mu \mathrm{L}$ extract for $6 \mathrm{~h}$. The solution was then adjusted to $100 \mathrm{mM}$ Tris, $100 \mathrm{mM}$ sodium acetate, $\mathrm{pH} 7.3$ and digested overnight with chondroitinase $\mathrm{ABC}$ at 50 milliunits $/ 25 \mu \mathrm{l}$ of extract. Sample buffer was added directly after digestions, and the proteins were fractionated on 4-12\% SDS-PAGE gradient gels. Proteins were transferred to nitrocellulose membranes and blocked with $1.5 \%(\mathrm{w} / \mathrm{v})$ skim milk powder in TBST $(0.01 \mathrm{M}$ Tris-HCl, $0.15 \mathrm{M} \mathrm{NaCl}, 0.1 \%$ Tween 20, pH 7.6). Antisera were diluted 1:1000 in the same buffer containing $3 \%$ bovine serum albumin (BSA). Immunoblotting was performed using specific polyclonal antibodies that were generated against the G1 domain of aggrecan, and anti-FVDIPEN and anti-NITEGE which detect MMP and aggrecanase specific aggrecan cleavage products, respectively (Roughley et al., 2012). Bound antibodies were detected by chemiluminescence using the ECL system, after incubation with a secondary antibody conjugated to horseradish peroxidise, using a LAS4000 image analyser (GE Healthcare, Baie d'Urfe, QC, Canada). ImageQuant TL software was used for pixel quantification.

\section{Histology}

Remaining disc tissue (after cores were taken) was fixed in $80 \%$ methanol overnight at $4{ }^{\circ} \mathrm{C}$. Additional $6 \mathrm{~mm}$ cores were excised (one from central NP and one from lateral AF tissue - Fig. 1C, yellow circles) from both noninjured and injured discs. Tissue cores were cryo-protected using consecutive incubations in $10 \%, 20 \%$ and $30 \%$ sucrose solutions at $4{ }^{\circ} \mathrm{C}$ for $30 \mathrm{~min}, 1 \mathrm{~h}$, and overnight, respectively and then embedded and frozen in Tissue-Tek O.C.T compound (Fisher Scientific, Whitby, ON, Canada). $15 \mu \mathrm{m}$ cryosections were dried at $37^{\circ} \mathrm{C}$ for $20 \mathrm{~min}$ and rehydrated with phosphate-buffered saline (PBS) for $10 \mathrm{~min}$. PBS was removed and samples were stained with safranin-O and fast green as described (Purmessur et al., 2013). Proteoglycan and collagen staining were visualised using a Zeiss (Oberkochen, Germany) LSM 510 META Axioplan 2 microscope and an accompanying CoolSnap (Tucson, AZ, USA) HQ CCD camera. Images 
were processed using ImageProPlus6 (Media Cybernetics, Rockville, MD, USA) software.

\section{Conditioned media analysis}

Collected conditioned media from non-injured and injured disc cultures was incubated over commercially available human cytokine antibody arrays according to manufacturer's instructions. Chemiluminescence detection was performed using the ECL reagent provided in the array kit and visualised with ImageQuant LAS4000 (GE Healthcare). ImageQuant TL software was used for pixel quantification. Background baseline noise was subtracted from all samples and results expressed as a ratio of factors released from injured discs versus factors released from non-injured discs. The expression ratios were assessed for each disc and the average of each group was calculated. The concentration of NGF, BDNF and IL-1 $\beta$ in the culture medium was quantified using enzymelinked immunosorbent assays (ELISA) according to manufacturers' instructions. Duplicate $100 \mu \mathrm{L}$ samples of each conditioned medium were incubated in ELISA plates overnight at $4{ }^{\circ} \mathrm{C}$. Colorimetric absorbance was measured with a Tecan Infinite M200 PRO (Tecan, Männedorf, Switzerland) and analysed with i-control 1.9 software (Tecan). Mean concentrations of each factor released by non-injured discs and injured discs were calculated.

\section{Induction of neurite outgrowth using conditioned media}

Rat pheocromocytoma, PC12 (ATCC) is a cell line that grows in semi-adherent round clusters in regular culture media. They flatten out, adhere to the plastic and differentiate towards a neuronal-like phenotype in the presence of NGF (Szeberenyi, 1996). PC12 cells also sprout axon-like projections, termed neurites, in the presence of NGF. We have previously used PC12 cells to assess the presence of neurotrophic factors released from degenerate human discs and mechanically stimulated IVD cells (Gawri et al., 2014; Krock et al., 2014). 2 x $10^{5}$ PC12 cells/well were seeded on 6-well culture dishes coated with $50 \mathrm{mg} / \mathrm{mL}$ collagen type I and $0.1 \%$ Poly-L-Lysine. Cells were allowed to attach to culture surfaces for $24 \mathrm{~h}$ in RPMI 1640 medium supplemented with $1 \%$ AntibioticAntimycotic solution, $5 \%$ foetal bovine serum (FBS) and $10 \%$ horse serum. After cell attachment, control wells were supplemented with RPMI media containing $0.1 \%$ serum $(0.05 \%$ horse serum and $0.05 \% \mathrm{FBS})$ and $50 \mathrm{ng} /$ $\mathrm{mL}$ recombinant NGF or sterile water vehicle. Remaining wells were supplemented with $1.5 \mathrm{~mL}$ non-injured and injured-disc conditioned media from all discs 3 days post-compression. Neurite outgrowth was monitored after 4 days. Three random phase-contrast images per sample were taken from each individual experiment $(n=3)$. Quantification of the number of cells with neurites was therefore averaged from 9 images $(3648 \times 2736$ pixels each, captured using a Zeiss Axiovert 40C microscope equipped with a Canon (Tokyo, Japan) Powershot A640 digital camera attached to a Zeiss MC80DX 1.0x tube adapter) for the -NGF, NGF, non-injured and injured conditioned media samples. The whole image area was used to count cells from each condition.

\section{Statistical analyses}

All statistical analyses were performed comparing injured samples to non-injured controls using paired $t$-tests from three independent experiments using three individual donors. All $p$ values less than 0.05 were considered to be statistically significant differences. Analyses were performed using Graphpad Prism 6.0 (Graphpad Software, La Jolla, CA, USA).

\section{Results}

\section{Acute injury of healthy human IVDs fractures endplates and induces significant cell death} For non-injured controls, $5 \%$ compression did not fracture endplates (Fig. 1A). To induce acute traumatic injury to isolated, healthy human IVDs, a single ramp compression to $30 \%$ strain was applied at $30 \%$ per second. This resulted in endplate fracture in all samples loaded with this protocol (Fig. 1A). The average peak stress applied to IVDs was calculated from stress-strain curves and found to be 0.212 $\pm 0.056 \mathrm{MPa}$ for non-injured discs and $1.002 \pm 0.256 \mathrm{MPa}$ for injured discs (Fig. 1B). Mechanical injury of IVDs caused significant cell death (Fig. 2A). After 14 days of culture post-loading, non-injured IVDs contained about $15 \%$ dead cells $(86.16 \pm 9.06 \%$ and $81.43 \pm 12.47 \%$ cell viability in the NP and AF, respectively) (Fig. 2B). Mechanical injury resulted in about 40-50\% cell death $(53.36 \pm 17.91 \%$ and $37.99 \pm 15.48 \%$ viability in the NP and AF respectively), which was significantly less than the non-injured controls ( $p=0.022$ and 0.017 respectively) (Fig. 2B). Data shown for AF are from lateral sections only as no differences in viability were observed between lateral and anterior AF samples (not shown).

\section{Acute mechanical injury of healthy human IVDs causes significant loss of proteoglycan}

Histological analysis of cryosections from NP and AF tissue (14 days post-loading) from non-injured IVDs showed abundant safranin-O staining, whereas NP and AF sections from injured tissue showed mostly fast-green staining (Fig. 3A). Total sulphated glycosaminoglycan (GAG) content remaining within non-injured NP tissue was $15.56 \pm 6.83 \mathrm{mg} / \mathrm{g}$ while total GAG content remaining within injured NP tissue was reduced to $9.49 \pm 2.64 \mathrm{mg} / \mathrm{g}$ tissue ( $p=0.07$ ) (Fig. 3B). AF tissue proteoglycan content varied greatly in both non-injured and injured discs (data not shown). Consequently, significantly more GAG $(4.62 \pm 0.26 \mathrm{mg} / \mathrm{mL} ;(p=0.0004)$ was detected within conditioned media from mechanically injured IVDs (3 days post-loading) compared to conditioned media from uninjured IVDs $(0.11 \pm 0.08 \mathrm{mg} / \mathrm{mL})$ (Fig. $3 \mathrm{C})$. GAG release to the media from the injured discs peaked at 3 days, decreased over time and reached levels comparable to the uninjured discs at 7 days post loading (data not shown).

\section{Acute mechanical injury to healthy IVDs increases enzymatic ECM degradation}

To investigate ECM integrity of the loaded IVDs, enzymatic proteoglycan degradation was assessed in NP tissue protein extracts from both non-injured and 
A

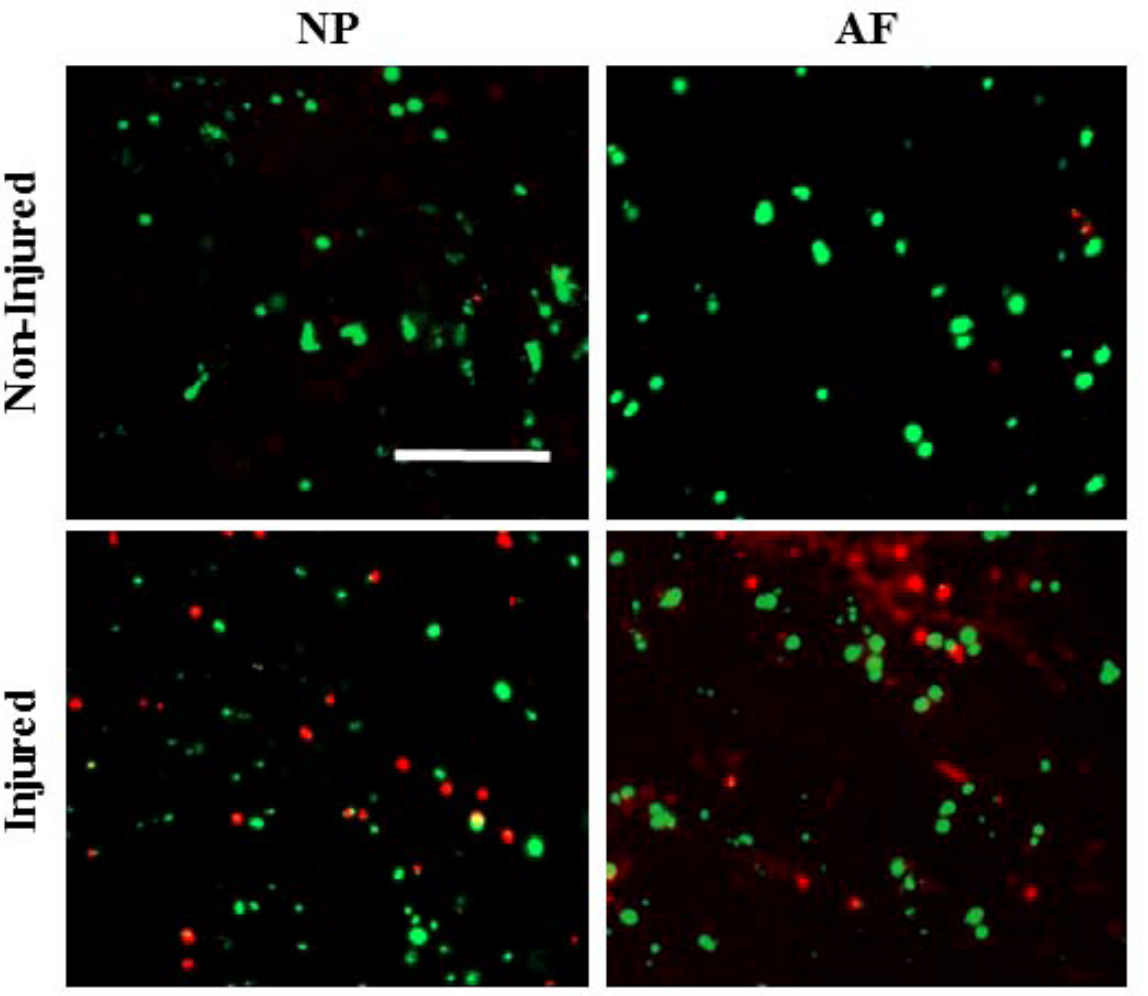

B

Cell Viability in NP Tissue

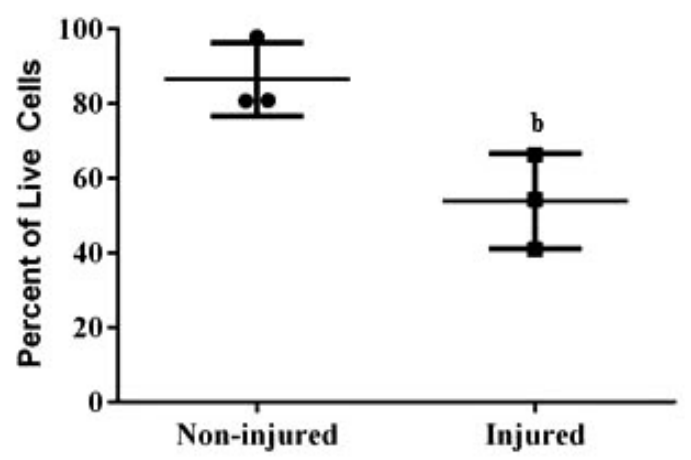

Cell Viability in AF Tissue

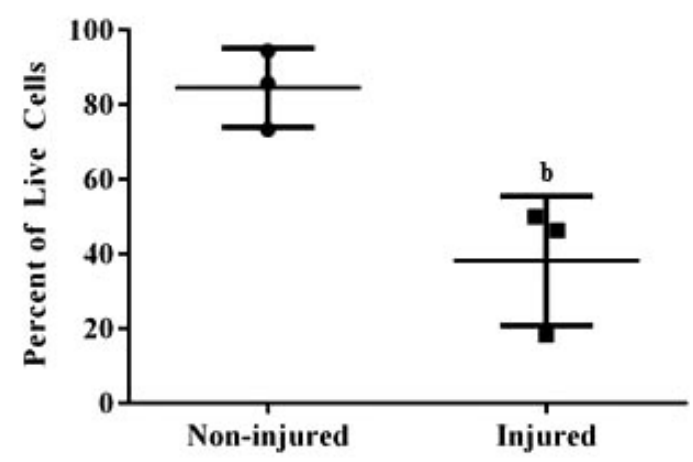

Fig. 2. Injurious mechanical loading causes significant IVD cell death. (A) Representative images of Live/Dead assays performed on non-injured and injured discs. Live (green) and dead (red) are shown. Cell viability was measured in 3 different tissue cores ( 2 AF and 1 NP) in non-injured and injured discs from three individual donors. The scale bars represent $200 \mu \mathrm{m}$. (B) The proportion of live to dead cells was quantified separately, and percentage of live cells was calculated from totals. Error bars indicate $\pm \mathrm{SD}, n=3 .{ }^{\mathbf{b}}$ indicates $p<0.05$ (paired $t$-test).

injured discs. Western blot analysis probing for specific proteolytic sites in the core protein of aggrecan revealed increased cleavage within the interglobular domain (IGD) in tissue extracts from injured discs compared to noninjured controls (Fig. 4A). Aggrecan cleavage products of $50 \mathrm{kDa}$ and $60 \mathrm{kDa}$ are known to be caused by MMP and aggrecanase activity, respectively (Roughley and Mort, 2012).Therefore, to affirm that the cleavage products observed were a result of MMP and aggrecanase cleavage, tissue extracts were probed with anti-neoepitope antibodies to both the MMP and aggrecanase cleavage sites. Increased MMP and aggrecanase cleavage products were observed in tissue extracts from injured discs as compared to extracts from non-injured discs (Fig. 4A). Densitometry analysis for the 3 individual donors ( 3 different tissue extracts) was performed. Injured disc tissue displayed about 2 times more aggrecanase and MMP (787 \pm 480 units, $p=0.114 ; 1203$ \pm 488 units, $p=0.0502$ ) cleavage products than non-injured discs respectively ( $387 \pm 82$ units; $548 \pm 68$ units), albeit with some donor variation (Fig. 4B). 
A
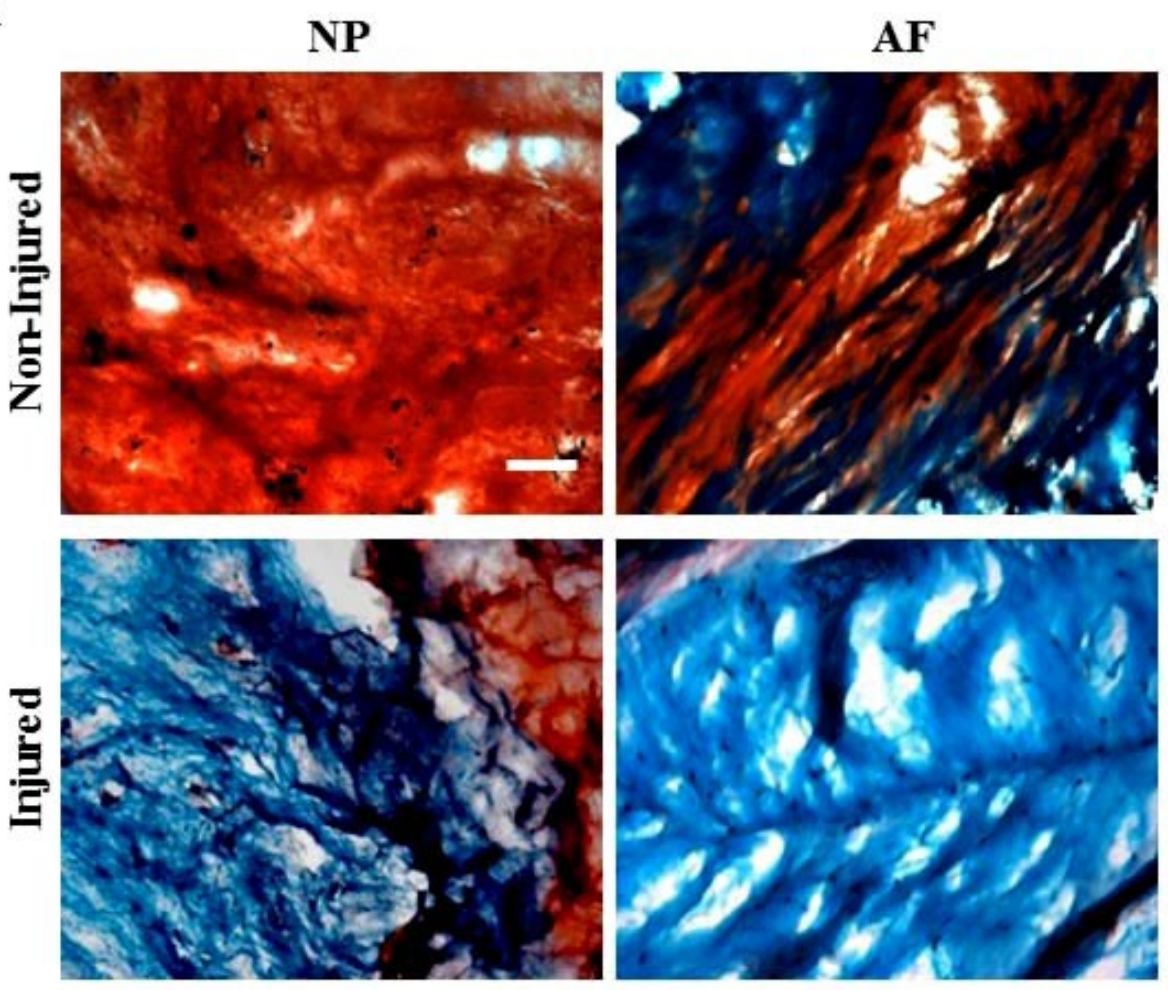

B

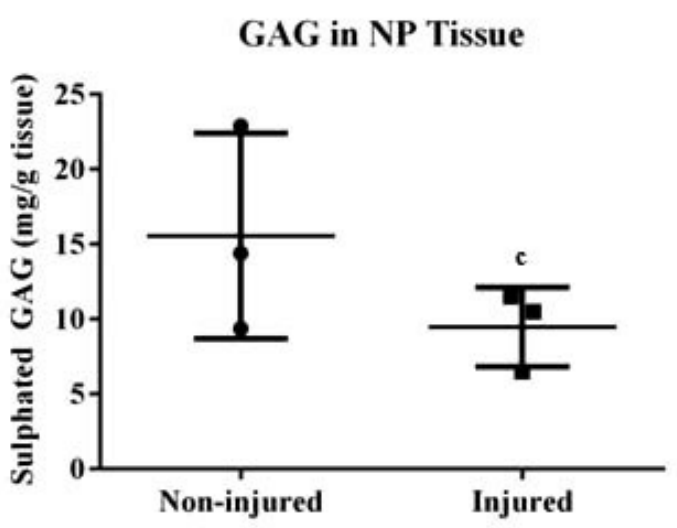

$\mathrm{C}$

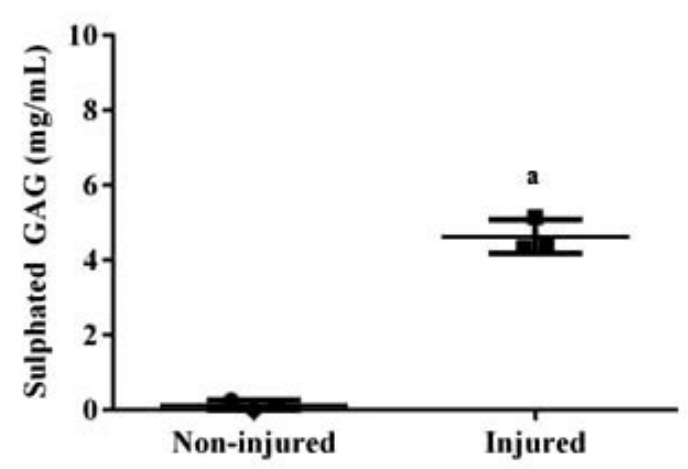

Fig. 3. Proteoglycan content within and released by injured and non-injured discs. (A) Representative histological sections of safranin-O/fast green staining of non-injured and injured disc tissue 14 days post-loading (scale bar, $200 \mu \mathrm{m}$ ). (B) Quantification of GAG content within non-injured and injured disc tissue. (C) Quantification of GAG released into conditioned media from non-injured and injured discs. Error bars indicate $\pm \mathrm{SD}, n=3$. ${ }^{\mathrm{a}}$ indicates $p<0.001,^{\mathrm{c}}$ indicates $p=0.07$ (paired $t$-test).

Acute mechanical injury promotes cytokine and neurotrophin release from healthy IVDs

Since inflammatory cytokines have been linked to degenerative disc disease, conditioned media from noninjured and injured discs were assessed for cytokine release. GRO- $\alpha$ (2.20 \pm 0.68 -fold; $p=0.04)$, IL-5 (1.61 \pm 0.38 -fold; $p=0.032)$, IL-6 (1.79 \pm 0.49 -fold; $p=0.034)$, IL-7 (1.65 \pm 0.32 -fold; $p=0.014)$, IL-8 $(1.52 \pm 0.31$-fold; $p=0.024)$, and MCP-2 (1.22 \pm 0.11 -fold; $p=0.018)$ levels were significantly elevated in conditioned media from injured
IVDs compared to non-injured controls (Fig. 5A). GRO $(1.31 \pm 0.28$-fold; $p=0.085)$ and MIG $(1.41 \pm 0.31$-fold; $p=0.057)$ showed trends for increased levels. Interestingly, IL-1 $\alpha(0.79 \pm 0.03$-fold; $p=0.00042)$ and TGF $\beta-1$ (0.69 \pm 0.19 -fold; $p=0.031$ ) were significantly decreased in conditioned media from injured discs.

Since increased inflammatory responses in degenerative disc disease have been correlated with back pain, conditioned media were analysed for factors implicated in inflammatory pain, NGF, TNF- $\alpha$, and BDNF (Fig. 5B). 


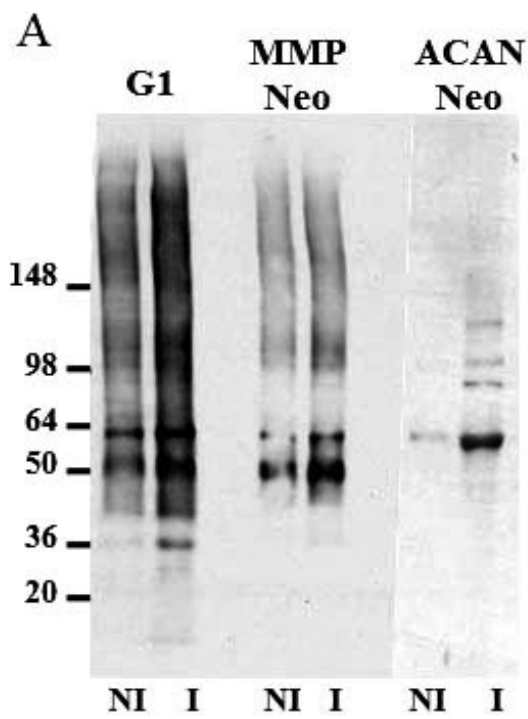

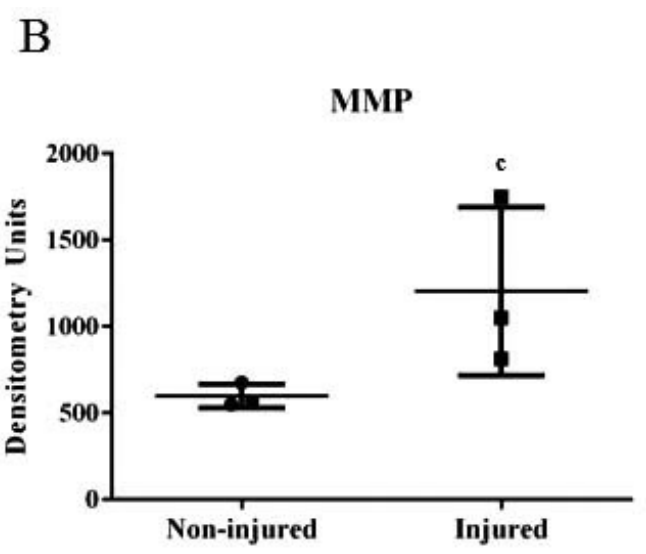

Aggrecanase

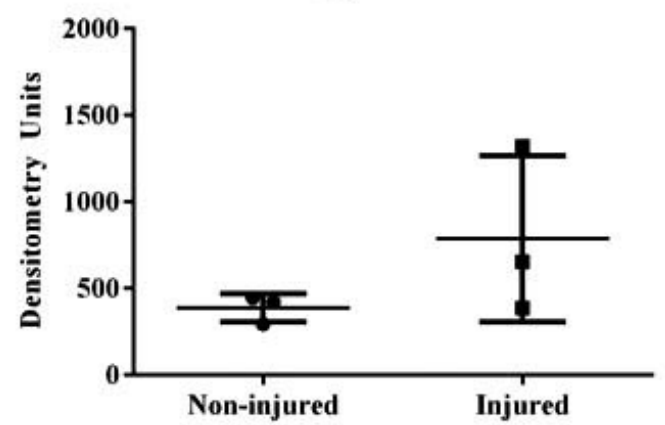

Fig. 4. Increased aggrecan degredation in injured human IVD tissue. (A) Representative SDS/PAGE immunoblot probed with polyclonal rabbit antibodies recognising the G1 domain of aggrecan (G1), a neo-epitope antibody recognising the MMP cleavage site of aggrecan (MMP Neo), and a neo-epitope antibody recognising the aggrecanase cleavage site of aggrecan (ACAN Neo). (B) Densitometry quantification of immunoblots. Error bars indicate \pm SD,

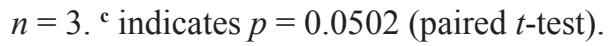

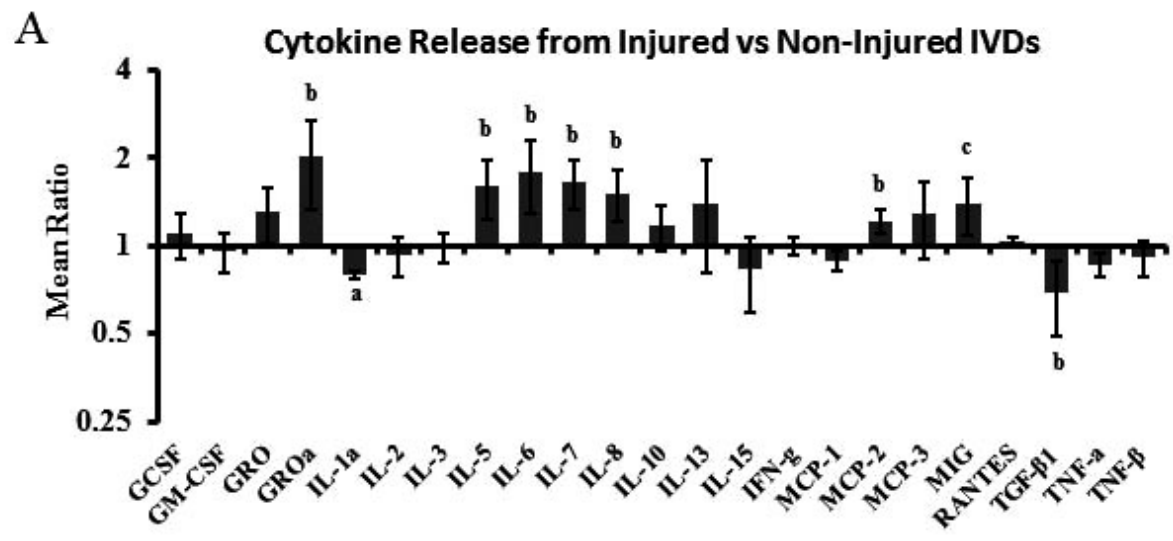

B
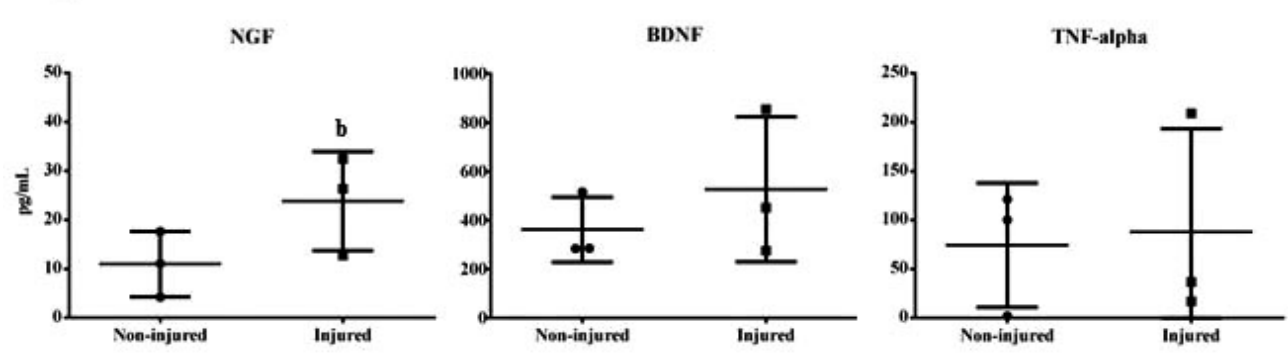

Fig. 5. Comparative analysis of factors released by injured and non-injured discs. (A) Media were analysed for released cytokines on a commercial array blot, and normalised to provided positive and negative controls and presented as the mean ratio. Data are plotted as factors released from injured discs versus non-injured discs 3 days post-loading. (B) ELISA analysis of conditioned culture media (3 days post-loading) from non-injured and injured discs. Error bars indicate $\pm \mathrm{SD}, n=3 .{ }^{\mathbf{a}}$ indicates $p<0.01 .{ }^{\mathbf{b}}$ indicates $p<0.05$; $^{\mathbf{c}}$ indicates $p=0.057$, paired $t$-test. 
A
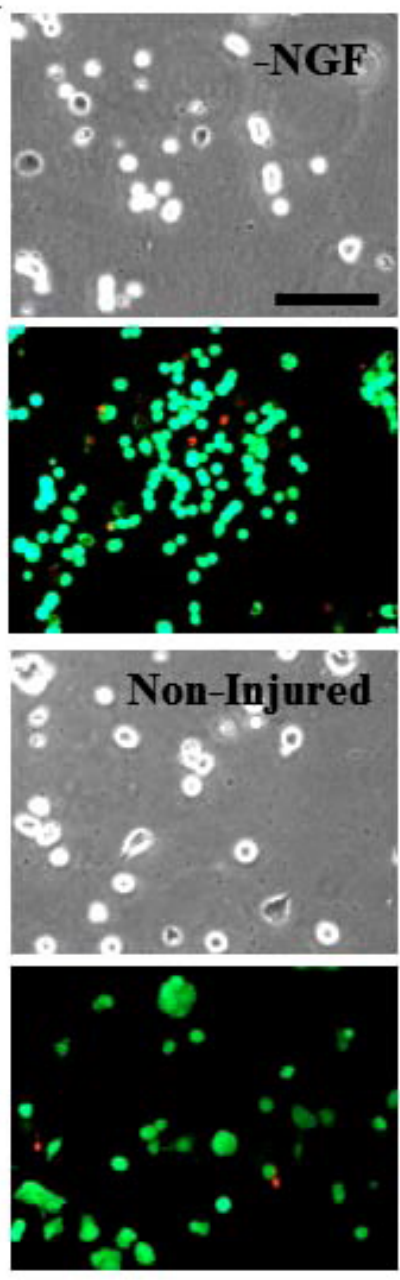
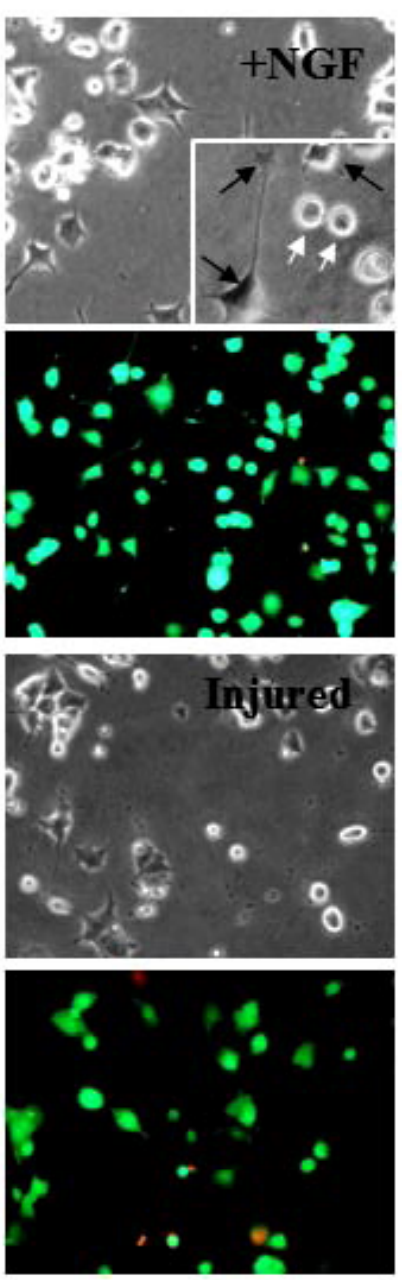

B

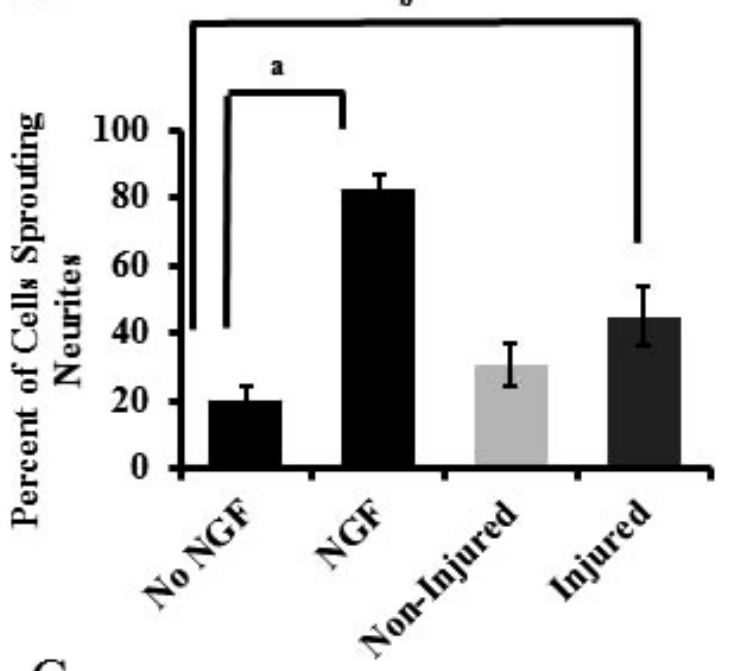

$\mathrm{C}$

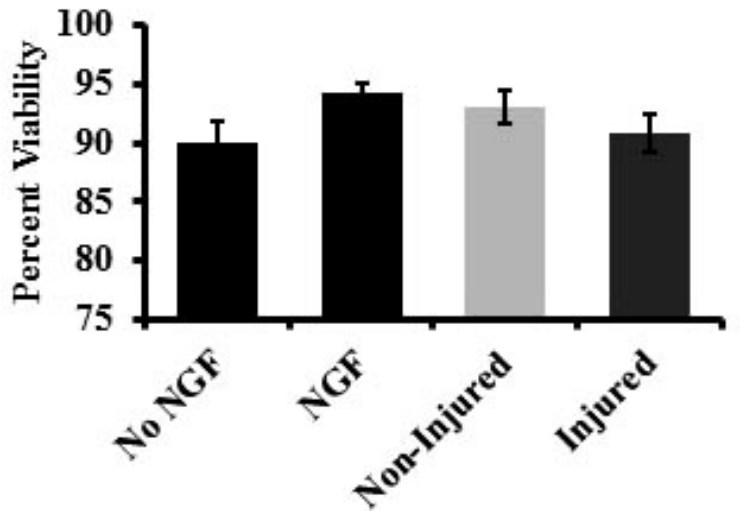

Fig. 6. Conditioned media from injured discs promote neurite outgrowth in PC12 cells. (A) Representative phase contrast and corresponding fluorescent LIVE/DEAD images of PC12 cells treated with sterile water vehicle (-NGF), $50 \mu \mathrm{g}$ of NGF (+NGF), non-injured conditioned media, or injured conditioned media. Inset panel shows magnified area indicating cells with neurites (black arrows) and those without neurites (white arrows). Red and green colour indicates dead and live cells respectively. Scale bar: $100 \mathrm{~mm}$. (B) Quantification of the proportion of cells sprouting neurites. (C) Quantification of cell viability. Error bars indicate \pm SD. ${ }^{a}$ and ${ }^{\mathbf{b}}$ indicate $p<0.001$ and 0.05 , respectively (paired $t$-test, $n=3$ in triplicate).

NGF was significantly elevated in injured disc conditioned media $(23.9 \pm 10.1 \mathrm{pg} / \mathrm{mL})$ as compared to non-injured disc conditioned media $(10.9 \pm 6.7 \mathrm{pg} / \mathrm{mL})(p=0.047)($ Fig. $5 B)$. TNF- $\alpha$ and BDNF levels were slightly increased in injured disc conditioned media compared to non-injured discs, however this was not statistically significant (Fig. 4B). Cytokine and neurotrophins were assessed at day 3 post-loading as preliminary data indicated that like for GAG release, their release peaked at day 3 .

\section{Conditioned media from acutely injured IVDs} induces neurite outgrowth in PC12 cells

To examine whether factors released from injured IVDs can stimulate neuronal differentiation, and potentially pain, conditioned media from injured and non-injured IVDs were applied to PC12 cells and neurite outgrowth was assessed. As a positive control, addition of recombinant NGF caused robust neurite outgrowth $(82.6 \pm 4.2 \%$; $p<0.001$ ) compared with untreated controls (which mainly remain rounded with no projections) $(20.4 \pm 4.1 \%)$ (Fig. $6 \mathrm{~B}$ ). Neurites were visualised as axon-like projections (Fig. $6 \mathrm{~A}$, indicated with black arrows in the inset). Media from injured discs caused significant neurite sprouting (44.8 $\pm 8.9 \% ; p=0.000016$ ) compared to untreated controls (Fig. 6B), while conditioned media from non-injured discs caused only slightly more PC12 neurite sprouting (30.6 $\pm 6.3 \%$ ) than untreated controls. Since released factors such as TNF $\alpha$ and IL-1 $\beta$ may potentially induce PC12 cell death, viability was assessed (Fig. 6A). Quantification of PC12 cell viability revealed that under all conditions, viability was above $90 \%$, with no statistical differences (Fig. 6C). 


\section{Discussion}

Mechanical injury and endplate fractures of IVDs have long been suspected to play a role in degenerative disc disease (Lotz and Ulrich, 2006; Adams et al., 2009; Adams and Dolan, 2011; Chan et al., 2011; Iatridis et al., 2013). Here, we demonstrate that acute mechanical injury initiates events associated with disc degeneration in an ex vivo healthy human whole-organ IVD culture model, which lends valuable support to the current body of literature. Loading schemes of non-injurious $5 \%$ strain $(\sim 0.2 \mathrm{MPa})$ and injurious $30 \%$ strain $(\sim 1.0 \mathrm{MPa})$ were applied at a high speed (30\% per second), simulating normal physiological and acute hyperphysiological compressions respectively. This study shows that acute mechanical injury to healthy human IVDs causes endplate fracture, increased cell death, upregulated proteolytic enzyme activity, significant proteoglycan loss, and increased expression of inflammatory cytokines capable of stimulating neurite outgrowth. Moreover, all injured discs were compared to respective non-injured discs isolated from the same individual donors.

Previous studies using cadaveric human lumbar spines have demonstrated that complex overloading of spinal motion segments can result in vertebral endplate fracture leading to reduced intradiscal pressure (Adams et al., 2000; Pollintine et al., 2004) which could lead to degeneration. Acute whiplash injuries are also thought to prematurely initiate degenerative disc disease (Hamer et al., 1993). Several in vitro models have been conducted focusing on injurious overloading of IVDs. High magnitude cyclical tensile loading of bovine caudal discs permanently disrupts the ECM (Iatridis et al., 2005), and wedge-loading of bovine caudal discs causes a catabolic shift within the ECM reminiscent of degeneration (Walter et al., 2011). Disc overload in an in vivo rat model also drives inflammation and degeneration (Miyagi et al., 2012). Traumatic impact loading of rabbit IVDs caused endplate fracture, increased cell death, and upregulated mRNA expression of several inflammatory and pain markers seen in disc degeneration (Dudli et al., 2012). While cyclic loading of 10-20\% strain can block catabolic activity of TNF and IL-6 in cartilage explants, dynamic strain above $30 \%$ inhibits this effect indicating an injurious threshold at $30 \%$ tissue strain (Li et al., 2013). The present study shows that a single, fast mechanical compression of $30 \%$ strain is sufficient to cause healthy human IVDs to immediately adapt a degenerate-like phenotype consisting of endplate fracture, proteoglycan cleavage and loss, and release of pro-inflammatory and neurotrophic factors. Taken together, our data suggests that acute trauma to IVDs may initiate events related to disc degeneration and pain in vivo.

IVD cell death has been previously demonstrated to be an important consequence of traumatic disc injury playing a direct role in degenerative disc disease. Using a custom drop-tower apparatus, two studies demonstrated that similar impact injuries (as applied here) can cause approximately 30-50\% cell death within injured discs (Dudli et al., 2012; Dudli et al., 2014). Studies have indicated that cell viability decreases in human discs as they age or become degenerate, likely contributing to matrix turnover and disc instability (Guiot et al., 2000). Moreover, surgical IVD samples from patients with traumatic injury showed up to $75 \%$ cell death (Sitte et al., 2009). Here, we demonstrate traumatic impact to human IVDs causes greater than $50 \%$ cell death in both the NP and the AF. These findings suggest that tissue necrosis plays an active role in disease progression, since the injured discs rapidly adopt a degenerate phenotype.

Proteoglycan fragmentation and loss in water content of human IVDs occur due to normal aging (Adams et al., 2000), yet when these events are accelerated they are hallmarks of early disc degeneration (Song et al., 2013). Proteoglycan degradation in osteoarthritic cartilage (Caterson et al., 1995) or degenerate discs (Sztrolovics et al., 1997) involves both aggrecanase and MMP cleavage of aggrecan serving as an indicator of matrix degradation. Moreover, proteoglycan degradation is apparent when adverse loading conditions are applied to intervertebral discs (Stokes and Iatridis, 2004; Paul et al., 2013). In various animal models, this evidence is also accompanied by elevated transcript levels of matrix degrading enzymes such as MMP and ADAMTS (Maclean et al., 2004; Gilbert et al., 2010; Sowa et al., 2011; Yurube et al., 2012). In agreement with these studies, our study demonstrates significant proteoglycan cleavage and reduction in GAG content in healthy human discs subjected to acute mechanical injury as compared to noninjured discs. Previous dynamic loading studies showed increased aggrecan fragmentation (Walter et al., 2011), and we demonstrate here that even a single traumatic event causes increased specific MMP and aggrecanase activity in healthy human discs thereby contributing to loss of GAG content. These data indicate that acute mechanical trauma and endplate fractures to human IVDs directly drives matrix fragmentation and reduced GAG content that could potentially initiate disc degeneration in vivo.

In conjunction with increased expression of catabolic proteases, previous studies have indicated that inflammatory cytokines are involved in degenerative disc disease and associated pain (Freemont et al., 2002; Navone et al., 2012; Krock et al., 2014). An in vivo rat disc injury model for degeneration and pain has been established, linking increased inflammation with chronic discogenic pain (Miyagi et al., 2011). Isolated IVD cells can also actively secrete these factors under various culture conditions (Yamauchi et al., 2009; Moon et al., 2012; Phillips et al., 2013; Gawri et al., 2014). In addition, exposure of IVD cells to inflammatory mediators can induce production of neurotrophic factors involved in neuronal and vascular growth (Abe et al., 2007; Gruber et al., 2012). Our data indicates the presence of increased cytokines and inflammatory factors post-injury. This increased inflammatory environment may be promoting the upregulated protease activity also observed post-injury (Wuertz and Haglund, 2013; Risbud and Shapiro, 2014). The present study demonstrates in real-time that high impact or adverse loading of otherwise healthy human IVDs is sufficient to induce the expression and release of inflammatory cytokines and neurotrophic factors associated with disc degeneration, neuronal and vascular infiltration and pain. Taken together, these data further 
suggest that acute disc trauma can result in an inflammatory environment which may enhance disease progression and promote back pain in vivo.

The cartilaginous endplate model (Gawri et al., 2011) we use in this study lacks several in vivo components of the spine, yet this ex vivo approach allows for direct study of the events and mechanisms causing an individual healthy human disc to acquire degenerate characteristics. Our cartilaginous endplate model allows for diffusion of nutrients and proteins into and out of the discs. Therefore conditioned culture media can be analysed for released matrix degradation products and expression of different inflammatory cytokines using western blotting, protein arrays and ELISA assays. The traumatic load applied in this study may not recapitulate exact trauma happening to individuals, it is however conceivable that very high magnitude and rapid impact resulting in endplate fractures might occur in automobile accidents, ski accidents or a fall from a height. These types of injuries could cause vertebral endplate fracture and decompression of the IVD which has been recently demonstrated (Dolan et al., 2013). Furthermore, it is known now that vertebral endplate fracture can promote disc degeneration by increased expression of catabolic factors such as MMPs and proinflammatory factors such as TNF- $\alpha$, IL-6, IL-8, MCP-1 using an in vitro rabbit IVD fracture model (Dudli et al., 2012). It has recently been demonstrated that loaded human organ culture experiments can be performed retaining the vertebral endplates (Walter et al., 2014) allowing future experiments including vertebral endplate fracture to be explored.

\section{Conclusions}

The present study shows a single hyperphysiological mechanical compression to healthy human IVDs causes endplate fracture, significant cell death, upregulated proteolytic enzyme activity, significant proteoglycan loss, and increased expression of inflammatory and neurotrophic cytokines. Interestingly, the profile of inflammatory cytokines released by the injured tissue are similar to those released by surgical samples removed from patients suffering painful disc degeneration. Factors released by the injured tissue are also known neurotrophins, capable of promoting neuronal growth and sensitisation. These data indicate that the acute mechanical injury of healthy human IVDs can promote early events associated with disc degeneration, inflammation and potential pain. Moreover, data obtained from these studies may provide new insights to better diagnostic and therapeutic approaches to spine injury, regenerative medicine and pain treatment. Future studies will focus on injury of tissue with vertebrae intact, to better model traumatic IVD injury as it occurs in vivo.

\section{Acknowledgements}

This work was supported by the Canadian Institutes of Health Research (CIHR) grant CIHR MOP-119564 and AOSpine, SRN_2011_04_10498. The authors would like extend thanks to Rahul Gawri for his role in harvesting IVDs from human organ donors. BA and DHR designed the study, conducted experiments, analysed data, interpreted results and wrote the manuscript. EK and LB contributed to experiments. MHW, JAO, TS and PJR helped to design the study and reviewed and revised manuscript. MHW and JAO provided organ donor IVD samples. LH designed the study, interpreted results, and wrote the manuscript. All authors approved of the final manuscript.

Disclosures: All authors disclose that there are no conflicts of interest.

\section{References}

Abe Y, Akeda K, An HS, Aoki Y, Pichika R, Muehleman C, Kimura T, Masuda K (2007) Proinflammatory cytokines stimulate the expression of nerve growth factor by human intervertebral disc cells. Spine (Phila Pa 1976) 32: 635-642.

Adams MA, Dolan P (2011) Biomechanics of vertebral compression fractures and clinical application. Arch Orthop Trauma Surg 131: 1703-1710.

Adams MA, Roughley PJ (2006) What is intervertebral disc degeneration, and what causes it? Spine (Phila $\mathrm{Pa}$ 1976) 31: 2151-2161.

Adams MA, Freeman BJ, Morrison HP, Nelson IW, Dolan P (2000) Mechanical initiation of intervertebral disc degeneration. Spine (Phila Pa 1976) 25: 1625-1636.

Adams MA, Dolan P, McNally DS (2009) The internal mechanical functioning of intervertebral discs and articular cartilage, and its relevance to matrix biology. Matrix Biol 28: 384-389.

Battie MC, Videman T, Gill K, Moneta GB, Nyman R, Kaprio J, Koskenvuo M (1991) 1991 Volvo award in clinical sciences. Smoking and lumbar intervertebral disc degeneration: An MRI study of identical twins. Spine (Phila Pa 1976) 16: 1015-1021.

Caterson B, Hughes CE, Roughley P, Mort JS (1995) Anabolic and catabolic markers of proteoglycan metabolism in osteoarthritis. Acta Orthop Scand Suppl 266: 121-124.

Chan SC, Ferguson SJ, Gantenbein-Ritter B (2011) The effects of dynamic loading on the intervertebral disc. Eur Spine J 20: 1796-1812.

Dolan P, Luo J, Pollintine P, Landham PR, Stefanakis M, Adams MA (2013) Intervertebral disc decompression following endplate damage: Implications for disc degeneration depend on spinal level and age. Spine (Phila Pa 1976) 38: 1473-1481.

Dudli S, Haschtmann D, Ferguson SJ (2012) Fracture of the vertebral endplates, but not equienergetic impact load, promotes disc degeneration in vitro. J Orthop Res 30: $809-816$.

Dudli S, Ferguson SJ, Haschtmann D (2014) Severity and pattern of posttraumatic intervertebral disc degeneration depends on the type of injury. Spine J 14: 1256-1264.

Fields AJ, Liebenberg EC, Lotz JC (2014) Innervation of pathologies in the lumbar vertebral end plate and intervertebral disc. Spine J 14: 513-521. 
Freemont AJ, Watkins A, Le Maitre C, Baird P, Jeziorska M, Knight MT, Ross ER, O’Brien JP, Hoyland JA (2002) Nerve growth factor expression and innervation of the painful intervertebral disc. J Pathol 197: 286-292.

Gardner-Morse MG, Stokes IA (2004) Structural behavior of human lumbar spinal motion segments. J Biomech 37: 205-212.

Gawri R, Mwale F, Ouellet J, Roughley PJ, Steffen T, Antoniou J, Haglund L (2011) Development of an organ culture system for long-term survival of the intact human intervertebral disc. Spine (Phila Pa 1976) 36: 1835-1842.

Gawri R, Rosenzweig DH, Krock E, Ouellet JA, Stone LS, Quinn TM, Haglund L (2014) High mechanical strain of primary intervertebral disc cells promotes secretion of inflammatory factors associated with disc degeneration and pain. Arthritis Res Ther 16: R21.

Gilbert HTJ, Hoyland JA, Millward-Sadler SJ (2010) The response of human anulus fibrosus cells to cyclic tensile strain is frequency-dependent and altered with disc degeneration. Arthritis Rheumatism 62: 3385-3394.

Gruber HE, Hoelscher GL, Hanley EN Jr. (2010) Annulus cells from more degenerated human discs show modified gene expression in $3 \mathrm{~d}$ culture compared with expression in cells from healthier discs. Spine J 10: 721727.

Gruber HE, Hoelscher GL, Bethea S, Hanley EN Jr. (2012) Interleukin 1-beta upregulates brain-derived neurotrophic factor, neurotrophin 3 and neuropilin 2 gene expression and NGF production in annulus cells. Biotech Histochem 87: 506-511.

Guiot BH, Fessler RG (2000) Molecular biology of degenerative disc disease. Neurosurgery 47: 1034-1040.

Haglund L, Moir J, Beckman L, Mulligan KR, Jim B, Ouellet JA, Roughley P, Steffen T (2011) Development of a bioreactor for axially loaded intervertebral disc organ culture. Tissue Eng Part C Methods 17: 1011-1019.

Hamer AJ, Gargan MF, Bannister GC, Nelson RJ (1993) Whiplash injury and surgically treated cervical disc disease. Injury 24: 549-550.

Iatridis JC, Maclean JJ, Ryan DA (2005) Mechanical damage to the intervertebral disc annulus fibrosus subjected to tensile loading. J Biomech 38: 557-565.

Iatridis JC, Nicoll SB, Michalek AJ, Walter BA, Gupta MS (2013) Role of biomechanics in intervertebral disc degeneration and regenerative therapies: What needs repairing in the disc and what are promising biomaterials for its repair? Spine J 13: 243-262.

Kelsey JL, Githens PB, White AA 3rd, Holford TR, Walter SD, O'Connor T, Ostfeld AM, Weil U, Southwick WO, Calogero JA (1984) An epidemiologic study of lifting and twisting on the job and risk for acute prolapsed lumbar intervertebral disc. J Orthop Res 2: 61-66.

Krock E, Rosenzweig DH, Chabot-Dore AJ, Jarzem P, Weber MH, Ouellet JA, Stone LS, Haglund L (2014) Painful, degenerating intervertebral discs up-regulate neurite sprouting and cgrp through nociceptive factors. J Cell Mol Med 18: 1213-1225.

Le Maitre CL, Freemont AJ, Hoyland JA (2005) The role of interleukin-1 in the pathogenesis of human intervertebral disc degeneration. Arthritis Res Ther 7: R732-745.
Li Y, Frank EH, Wang Y, Chubinskaya S, Huang HH, Grodzinsky AJ (2013) Moderate dynamic compression inhibits pro-catabolic response of cartilage to mechanical injury, tumor necrosis factor-alpha and interleukin-6, but accentuates degradation above a strain threshold. Osteoarthritis Cartilage 21: 1933-1941.

Lotz JC, Ulrich JA (2006) Innervation, inflammation, and hypermobility may characterize pathologic disc degeneration: Review of animal model data. J Bone Joint Surg Am 88 Suppl 2: 76-82.

Maclean JJ, Lee CR, Alini M, Iatridis JC (2004) Anabolic and catabolic mrna levels of the intervertebral disc vary with the magnitude and frequency of in vivo dynamic compression. J Orthop Res 22: 1193-1200.

Manchikanti L, Singh V, Datta S, Cohen SP, Hirsch JA (2009) Comprehensive review of epidemiology, scope, and impact of spinal pain. Pain Physician 12: E35-70.

Miyagi M, Ishikawa T, Orita S, Eguchi Y, Kamoda H, Arai G, Suzuki M, Inoue G, Aoki Y, Toyone T, Takahashi K, Ohtori S (2011) Disk injury in rats produces persistent increases in pain-related neuropeptides in dorsal root ganglia and spinal cord glia but only transient increases in inflammatory mediators: Pathomechanism of chronic diskogenic low back pain. Spine (Phila Pa 1976) 36: 22602266.

Miyagi M, Ishikawa T, Kamoda H, Suzuki M, Murakami K, Shibayama M, Orita S, Eguchi Y, Arai G, Sakuma Y, Kubota G, Oikawa Y, Ozawa T, Aoki Y, Toyone T, Takahashi K, Inoue G, Kawakami M, Ohtori S (2012) Issls prize winner: Disc dynamic compression in rats produces long-lasting increases in inflammatory mediators in discs and induces long-lasting nerve injury and regeneration of the afferent fibers innervating discs: A pathomechanism for chronic discogenic low back pain. Spine (Phila Pa 1976) 37: 1810-1818.

Moon HJ, Kim JH, Lee HS, Chotai S, Kang JD, Suh JK, Park YK (2012) Annulus fibrosus cells interact with neuron-like cells to modulate production of growth factors and cytokines in symptomatic disc degeneration. Spine (Phila Pa 1976) 37: 2-9.

Mort JS, Roughley PJ (2007) Measurement of glycosaminoglycan release from cartilage explants. Methods Mol Med 135: 201-209.

Navone SE, Marfia G, Canzi L, Ciusani E, Canazza A, Visintini S, Campanella R, Parati EA (2012) Expression of neural and neurotrophic markers in nucleus pulposus cells isolated from degenerated intervertebral disc. J Orthopaed Res 30: 1470-1477.

Paul CP, Schoorl T, Zuiderbaan HA, Zandieh Doulabi B, van der Veen AJ, van de Ven PM, Smit TH, van Royen BJ, Helder MN, Mullender MG (2013) Dynamic and static overloading induce early degenerative processes in caprine lumbar intervertebral discs. PLoS One 8: e62411.

Phillips KL, Chiverton N, Michael AL, Cole AA, Breakwell LM, Haddock G, Bunning RA, Cross AK, Le Maitre CL (2013) The cytokine and chemokine expression profile of nucleus pulposus cells: Implications for degeneration and regeneration of the intervertebral disc. Arthritis Res Ther 15: R213.

Pollintine P, Dolan P, Tobias JH, Adams MA (2004) Intervertebral disc degeneration can lead to "stress- 
shielding" of the anterior vertebral body: A cause of osteoporotic vertebral fracture? Spine (Phila Pa 1976) 29: 774-782.

Purmessur D, Freemont AJ, Hoyland JA (2008) Expression and regulation of neurotrophins in the nondegenerate and degenerate human intervertebral disc. Arthritis Res Ther 10: R99.

Purmessur D, Guterl CC, Cho SK, Cornejo MC, Lam YW, Ballif BA, Laudier JC, Iatridis JC (2013) Dynamic pressurization induces transition of notochordal cells to a mature phenotype while retaining production of important patterning ligands from development. Arthritis Res Ther 15: R122.

Richardson SM, Doyle P, Minogue BM, Gnanalingham K, Hoyland JA (2009) Increased expression of matrix metalloproteinase-10, nerve growth factor and Substance $\mathrm{P}$ in the painful degenerate intervertebral disc. Arthritis Res Ther 11: R126.

Richardson SM, Purmessur D, Baird P, Probyn B, Freemont AJ, Hoyland JA (2012) Degenerate human nucleus pulposus cells promote neurite outgrowth in neural cells. PLoS One 7: e47735.

Risbud MV, Shapiro IM (2014) Role of cytokines in intervertebral disc degeneration: Pain and disc content. Nat Rev Rheumatol 10: 44-56.

Roughley PJ (2004) Biology of intervertebral disc aging and degeneration: Involvement of the extracellular matrix. Spine (Phila Pa 1976) 29: 2691-2699.

Roughley PJ, Mort JS (2012) Analysis of aggrecan catabolism by immunoblotting and immunohistochemistry. Methods Mol Biol 836: 219-237.

Sitte I, Kathrein A, Pfaller K, Pedross F, Roberts S (2009) Intervertebral disc cell death in the porcine and human injured cervical spine after trauma: A histological and ultrastructural study. Spine (Phila Pa 1976) 34: 131140.

Song YQ, Karasugi T, Cheung KM, Chiba K, Ho DW, Miyake A, Kao PY, Sze KL, Yee A, Takahashi A, Kawaguchi Y, Mikami Y, Matsumoto M, Togawa D, Kanayama M, Shi D, Dai J, Jiang Q, Wu C, Tian W, Wang N, Leong JC, Luk KD, Yip SP, Cherny SS, Wang J, Mundlos S, Kelempisioti A, Eskola PJ, Mannikko M, Makela P, Karppinen J, Jarvelin MR, O’Reilly PF, Kubo M, Kimura T, Kubo T, Toyama Y, Mizuta H, Cheah KS, Tsunoda T, Sham PC, Ikegawa S, Chan D (2013) Lumbar disc degeneration is linked to a carbohydrate sulfotransferase 3 variant. J Clin Invest 123: 4909-4917.

Sowa GA, Coelho JP, Bell KM, Zorn AS, Vo NV, Smolinski P, Niyonkuru C, Hartman R, Studer RK, Kang JD (2011) Alterations in gene expression in response to compression of nucleus pulposus cells. Spine J 11: 36-43.

Stefanakis M, Al-Abbasi M, Harding I, Pollintine P, Dolan P, Tarlton J, Adams MA (2012) Annulus fissures are mechanically and chemically conducive to the ingrowth of nerves and blood vessels. Spine (Phila Pa 1976) 37: 1883-1891.

Stokes IA, Iatridis JC (2004) Mechanical conditions that accelerate intervertebral disc degeneration: Overload versus immobilization. Spine (Phila $\mathrm{Pa} 1976$ ) 29: 27242732.
Szeberenyi J (1996) Gene activation pathways of nerve growth factor signaling: A minireview. Neurobiology (Bp) 4: 1-11.

Sztrolovics R, Alini M, Roughley PJ, Mort JS (1997) Aggrecan degradation in human intervertebral disc and articular cartilage. Biochem J 326: 235-241.

Videman T, Sarna S, Battie MC, Koskinen S, Gill K, Paananen H, Gibbons L (1995) The long-term effects of physical loading and exercise lifestyles on back-related symptoms, disability, and spinal pathology among men. Spine (Phila Pa 1976) 20: 699-709.

Walter BA, Illien-Junger S, Nasser PR, Hecht AC, Iatridis JC (2014) Development and validation of a bioreactor system for dynamic loading and mechanical characterization of whole human intervertebral discs in organ culture. J Biomech 47: 2095-2101.

Walter BA, Korecki CL, Purmessur D, Roughley PJ, Michalek AJ, Iatridis JC (2011) Complex loading affects intervertebral disc mechanics and biology. Osteoarthritis Cartilage 19: 1011-1018.

Wang Y, Videman T, Battie MC (2012) Issls prize winner: Lumbar vertebral endplate lesions: Associations with disc degeneration and back pain history. Spine (Phila Pa 1976) 37: 1490-1496.

Wuertz K, Haglund L (2013) Inflammatory mediators in intervertebral disk degeneration and discogenic pain. Global Spine J 3: 175-184.

Yamauchi K, Inoue G, Koshi T, Yamashita M, Ito T, Suzuki M, Eguchi Y, Orita S, Takaso M, Nakagawa K, Aoki Y, Ochiai N, Kishida S, Endo M, Yamashita T, Takahashi K, Ohtori S (2009) Nerve growth factor of cultured medium extracted from human degenerative nucleus pulposus promotes sensory nerve growth and induces Substance P in vitro. Spine 34: 2263-2269.

Yurube T, Takada T, Suzuki T, Kakutani K, Maeno K, Doita M, Kurosaka M, Nishida K (2012) Rat tail static compression model mimics extracellular matrix metabolic imbalances of matrix metalloproteinases, aggrecanases, and tissue inhibitors of metalloproteinases in intervertebral disc degeneration. Arthritis Res Ther 14: R51.

\section{Discussion with Reviewers}

S. Grad: Removal of vertebral endplates and rapid loading are artificial conditions used in this model system. How do the cartilage endplate injuries observed in this study compare with endplate defects observed on human histology, or Modic changes observed on MRI in clinical patients?

Authors: It is difficult to make a direct correlation to the in vivo situation, however, experimental rapid loading causing fracture to the cartilage endplate most likely mimics an acute injury. We performed preliminary experiments where the cartilage endplate was cut open without a mechanical injury and could not see an increase in proteinases, cytokines or pain mediators, whereas non-aggregating proteoglycan rapidly diffused from the tissue into the culture medium. Based on this one would speculate that endplate fracture, Modic changes or any defect or increased 
permeability of the cartilage endplate would facilitate proteoglycan loss, which with time would lead to altered tissue properties and perhaps non-physiologic stress on the cells, that in turn could result in increased proteinase, cytokine and pain mediator production.

J. Iatridis: It is interesting to note that the release of cytokines appeared to peak at day 3 after injury. This suggests a natural reaction to acute tissue damage that is generally regarded as beneficial for inducing a repair response. In contrast, a sustained inflammatory state has been associated with progressive degenerative diseases. Does the outcome suggest an entirely catabolic response, or is a certain anabolic reaction likely at later time points? Authors: The reviewer raises and interesting and valid point. It is indeed true that acute inflammatory responses after injury are involved in tissue repair processes, while chronic or prolonged inflammatory environment can play a direct role in disease progression. Our experiments are conducted in an open ex vivo culture system where inflammatory factors are released into the culture medium. We replenish culture media every 3 days with the consequence that the released inflammatory factors are being removed or at least diluted - making it difficult to fully address the question. Nonetheless, the observation that enzymatic matrix degradation is occurring also at 14 days suggests a sustained catabolic environment. Had the study been conducted in vivo in a "closed system", we suspect that the elevated levels of inflammatory factors and proteinases could possibly generate matrix fragments activating Toll-like receptors and would remain within the tissue driving stronger and more sustained responses. Only further studies on acute disc trauma in a large animal model would be able to fully address whether or not the response is sustained and results in degeneration. 